\title{
Pim-3 alleviates lipopolysaccharide-stimulated AR42J pancreatic acinar cell injury via improving the inflammatory microenvironment
}

\author{
JIE JIAN，SHUANG LI，NIAN FANG，YOU-ZHAO CAO，LI ZHEN，JIAN-BIN QIN and BIN LI
}

Department of Gastroenterology, The Third Affiliated Hospital of Nanchang University, Nanchang, Jiangxi 330008, P.R. China

Received February 13, 2019; Accepted September 24, 2019

DOI: $10.3892 /$ etm.2019.8094

\begin{abstract}
Acute pancreatitis (AP) is a common acute abdominal disease characterized by pancreatic aseptic inflammation, with $\sim 20 \%$ of patients progressing to severe AP (SAP) with a high mortality rate. The aim of this study was to explore the protective effects of Pim-3 proto-oncogene, serine/threonine kinase (Pim-3) on rat pancreatic acinar AR4-2J cells damaged by lipopolysaccharide (LPS). The recombinant plasmid p-enhanced green fluorescent protein (pEGFP)-N2/Pim-3 was transiently transfected into AR42J cells and the AR42J cells were then treated with $2 \mu \mathrm{g} / \mathrm{ml}$ LPS. Subsequently, the proliferation of AR42J cells was detected using MTT assay. The cell cycle progression and apoptosis rate of the AR42J cells were examined using flow cytometry. AR42J cell migration was assessed using wound healing assays. Additionally, RT-semi quantitative PCR and western blot analyses were used to detect the mRNA and protein expression levels, respectively, of Pim-3, interleukin (IL)-6, IL-1 $\beta$, tumor necrosis factor (TNF)- $\alpha$, intercellular adhesion molecule (ICAM)-1 and Occludin in AR42J cells. The results revealed that proliferation of AR42J cells was significantly enhanced and cell apoptosis was markedly reduced in the pEGFP-N2/Pim-3 + LPS group. The proportion of AR42J cells in G1 phase in the pEGFP-N2/Pim-3 + LPS group was decreased, whereas the proportion of cells in the $\mathrm{G} 2$ and $\mathrm{S}$ phases was increased. The wound healing assays demonstrated that AR42J cell migration was significantly increased in the pEGFP-N2/Pim-3 + LPS group. Finally, the expression levels of IL-6, IL-1 $\beta$, TNF- $\alpha$ and ICAM-1 were significantly decreased in the pEGFP-N2/Pim-3 + LPS group, whereas the expression of Occludin was significantly increased. The present study demonstrated that raised expression levels of Pim-3 can protect AR42J cells from
\end{abstract}

Correspondence to: Dr Nian Fang, Department of Gastroenterology, The Third Affiliated Hospital of Nanchang University, 128 Xiangshan North Road, Nanchang, Jiangxi 330008, P.R. China E-mail: fnian3893@126.com

Key words: Pim-3 proto-oncogene, serine/threonine kinase, lipopolysaccharide, proliferation, apoptosis, migration
LPS-induced injury by modifying the inflammatory microenvironment, suggesting that Pim-3 may be a potential target for AP or SAP therapy.

\section{Introduction}

Acute pancreatitis (AP) is a common acute abdominal disease characterized by pancreatic inflammation, ranging from mild edema to severe tissue necrosis (1). Severe AP (SAP) is the most serious type of AP, due to its high morbidity and mortality (2). In recent years, the incidence of pancreatitis has increased worldwide. However, the pathophysiological mechanism behind AP is currently not fully understood. The protection of damaged pancreatic cells remains an important treatment for AP (3). Previous studies have focused on developing drug therapies for AP, such as drugs that inhibit pancreatic secretions, suppress acid secretion or have anti-inflammatory effects (4-6). However, for severe necrotizing pancreatitis, drug treatment is ineffective and mortality remains high. At present, researchers are investigating the molecular mechanisms and developing gene therapies for the treatment of AP or SAP (7-9).

Pim-3 proto-oncogene, serine/threonine kinase (Pim-3) is a highly conserved serine/threonine kinase, which was originally considered to be a depolarization-inducing gene with numerous biological activities (10). Studies have reported that Pim-3 is highly expressed in a variety of endoderm-derived cancers, such as hepatocellular carcinoma, pancreatic cancer and colon cancer (11-14). Pim-3 promotes cell proliferation and prevents apoptosis through the phosphorylation and inactivation of the apoptosis-promoting protein, BAD (15). In addition, it has been confirmed that Pim-3 expression is significantly upregulated in abnormally proliferative pancreata, and the apoptosis of pancreatic cells is significantly enhanced after Pim-3 gene knockout (13). Recent studies have shown that Pim-3 exerts protective effects on fulminant hepatic failure, intestinal mucosal damage and lipopolysaccharide (LPS)-stimulated hepatic stellate cell injury (16-18).

Based on the aforementioned evidence, it was speculated that Pim-3 has a beneficial effect on pancreatic acinar cell injury. The purpose of the present study was to investigate the protective effect of Pim-3 on pancreatic cell injury induced by LPS and to investigate its potential mechanism. 


\section{Materials and methods}

Materials and reagents. Rat pancreatic acinar AR42J cells were obtained from the American Type Culture Collection. Ham's F12 medium and LPS were purchased from Sigma-Aldrich; Merck KGaA. FBS was purchased from Gibco; Thermo Fisher Scientific, Inc. Vacant vector plasmid p-enhanced green fluorescent protein (pEGFP)-N2 and the recombinant plasmid pEGFP-N2/Pim-3 were provided generously by Jiangxi Provincial Key Laboratory of Molecular Medicine; these plasmids were described in previous studies $(16,17)$. Liposome (Lipofectamine $^{\circledR} 2000$ ) and TRIzol ${ }^{\circledR}$ were purchased from Invitrogen; Thermo Fisher Scientific, Inc. G418 and MTT were purchased from Beijing Solarbio Science \& Technology Co., Ltd. Annexin V-FITC was purchased from Invitrogen; Thermo Fisher Scientific, Inc. Propidium iodide (PI) was purchased from Sigma-Aldrich; Merck KGaA. DMSO was purchased from Amresco, LLC. Reverse transcription (RT) kit (M-MLV kit) was purchased from Fermentas; Thermo Fisher Scientific, Inc. PCR primers were synthesized by Generay Biotech Co., Ltd. 2X Taq PCR Master Mix was purchased from Tiangen Biotech Co., Ltd. Total protein extraction kit was purchased from Sangon Biotech Co., Ltd. BCA assay kit was purchased from Sigma-Aldrich; Merck KGaA. Anti-Pim-3 (cat. no. 4165; 1:1,000) primary antibody was purchased from Cell Signaling Technology. Primary antibodies against interleukin (IL)-6 (cat. no. sc-57315; 1:1,000), IL-1 $\beta$ (cat. no. sc-4592; 1:1,000), tumor necrosis factor (TNF)- $\alpha$ (cat. no. sc-12744; 1:1,000), intercellular adhesion molecule (ICAM)-1 (cat. no. sc-8439; 1:1,000), Occludin (cat. no. sc-133256; 1:1,000) and $\beta$-actin (cat. no. sc-81178; 1:1,000) were purchased from Santa Cruz Biotechnology, Inc. Horseradish peroxidase-conjugated secondary antibodies were purchased from OriGene Technologies, Inc.

Cell culture. AR42J cells were maintained in Ham's F12 medium containing $10 \% \mathrm{FBS}, 100 \mathrm{U} / \mathrm{ml}$ penicillin, $100 \mu \mathrm{g} / \mathrm{ml}$ streptomycin and $400 \mu \mathrm{g} / \mathrm{ml} \mathrm{G} 418$. The cells were routinely plated at a density of $1 \times 10^{5}$ cells $/ \mathrm{ml}$ in 6-well cluster dishes and incubated in a humidified incubator at $37^{\circ} \mathrm{C}$ with $95 \%$ atmospheric air and $5 \% \mathrm{CO}_{2}$.

Transfection and LPS treatment. Prior to plasmid transfection, $1 \times 10^{5}$ AR42J cells were seeded onto a $35 \mathrm{~mm}$-dish in $2 \mathrm{ml} \mathrm{Ham}$ 's F-12 medium supplemented with $10 \%$ FBS, without antibiotics, and cultured to $90 \%$ confluence at $37^{\circ} \mathrm{C}$ with $95 \%$ air and $5 \% \mathrm{CO}_{2}$. The cells were subsequently transfected with $4 \mu \mathrm{g} / \mathrm{ml}$ pEGFP-N2 or pEGFP-N2/Pim-3 in the presence of Lipofectamine ${ }^{\circledR} 2000$ at room temperature. In the control group, culture medium alone was added to the cells. After $4 \mathrm{~h}$, the medium was refreshed with Ham's F12 medium containing $10 \%$ FBS, and the cells were incubated for $48 \mathrm{~h}$ at $37^{\circ} \mathrm{C}$ with $95 \%$ air and $5 \% \mathrm{CO}_{2}$. GFP was observed under a fluorescence microscope. The proliferation of AR42J cells treated with various concentrations of LPS (24, 36 and $48 \mathrm{~h}$ ) was analyzed, and the $2 \mu \mathrm{g} / \mathrm{ml}$ dose was selected for subsequent experiments. After plasmid transfection, AR42J cells were divided into six groups for subsequent experiments: i) Control group, untransfected AR42J cells without LPS treatment; ii) LPS group, untransfected AR42J cells treated with $2 \mu \mathrm{g} / \mathrm{ml}$ LPS; iii) pEGFP-N2 group, AR42J cells transfected with empty vector pEGFP-N2; iv) pEGFP-N2 + LPS group, AR42J cells transfected with empty vector pEGFP-N2 and treated with $2 \mu \mathrm{g} / \mathrm{ml}$ LPS; v) pEGFP-N2/Pim-3 group, AR42J cells transfected with recombinant plasmid pEGFP-N2/Pim-3; and vi) pEGFP-N2/Pim-3 + LPS group, AR42J cells transfected with recombinant plasmid pEGFP-N2/Pim-3 and treated with $2 \mu \mathrm{g} / \mathrm{ml}$ LPS.

MTT assay. AR42J cells in each group were treated with LPS for 24,36 and $48 \mathrm{~h}$ at $37^{\circ} \mathrm{C}$ with $95 \%$ air and $5 \% \mathrm{CO}_{2}$, and then $1 \times 10^{4}$ cells/well were inoculated in a 96-well culture plate. The cells were washed with PBS and incubated with $5 \mathrm{mg} / \mathrm{ml}$ MTT in $20 \mu \mathrm{l} \mathrm{PBS}$ at $37^{\circ} \mathrm{C}$ for $4 \mathrm{~h}$. Subsequently, $150 \mu \mathrm{l}$ DMSO was added to stop the reaction. The absorbance was measured at $492 \mathrm{~nm}$ using a spectrophotometer after $10 \mathrm{~min}$. Each independent experiment was performed three times and data are presented as mean $\pm \mathrm{SD}$.

Detection of apoptosis. After $48 \mathrm{~h}$ of LPS treatment, the AR42J cells in each group were trypsinized and collected by centrifugation at $37^{\circ} \mathrm{C}$ for $5 \mathrm{~min}$ at a speed of $1,000 \mathrm{x}$. The cells were washed twice with PBS. At least $1 \times 10^{5}$ cells were re-suspended in $500 \mu \mathrm{l}$ binding buffer (Invitrogen; Thermo Fisher Scientific, Inc.). Annexin V-FITC (5 $\mu \mathrm{l})$ and $5 \mu \mathrm{l}$ PI were added to the cell suspension. Finally, the cells were incubated in the dark at room temperature for $15 \mathrm{~min}$. A FACSCalibur flow cytometer (BD Biosciences) was used to detect the apoptotic rate of cells, including the early apoptotic rate (right lower quadrant) and the late apoptotic rate (right upper quadrant). BD CellQuest ${ }^{\mathrm{TM}}$ Pro software version 5.1 (BD Biosciences) was used to analyze the data.

Cell cycle assay. After $48 \mathrm{~h}$ of LPS treatment, AR42J cells in each group were digested with trypsin and collected by centrifugation at $37^{\circ} \mathrm{C}$ for $5 \mathrm{~min}$ at a speed of $1,000 \mathrm{x} \mathrm{g}$. The supernatant was subsequently discarded, and the cells were washed 3 times with PBS. The cells were incubated with propidium iodide (PI) stain buffer for $10 \mathrm{~min}$ and then treated with $200 \mu 1$ of PBS, $200 \mu \mathrm{l}$ of RNase A and $200 \mu \mathrm{l}$ of PI for $10 \mathrm{~min}$ at $4^{\circ} \mathrm{C}$ in the dark. Finally, the distribution of cells in each of the cell cycle phases were analyzed using a FACSCalibur flow cytometer (BD Biosciences). Data were acquired and analyzed using the ModFit ${ }^{\mathrm{TM}}$ software (version 4.1; Verity Software House, Inc.).

Wound healing assay. Following transfection, AR42J cells were seeded at $4 \times 10^{5}$ per well in 12 -well plates and incubated at $37^{\circ} \mathrm{C}$ to reach $100 \%$ confluence. A longitudinal scratch of equal width was created by scratching the cell surface with a $1 \mathrm{ml}$ pipette tip. The floating cells were washed away with PBS. Subsequently, the cells were incubated with Ham's F-12 with $2 \%$ FBS and $2 \mu \mathrm{g} / \mathrm{ml}$ LPS for $48 \mathrm{~h}$ at $37^{\circ} \mathrm{C}$. The wound healing was observed under a light microscope, and the image of the closed area was taken immediately after injury. The ability of cells to close the wound was calculated by measuring the average distance between the wound edge of the scratched space and calculating the percentage closure compared to the starting width through the equation: $(0-48 \mathrm{~h}) / 0 \mathrm{~h} \times 100$. Each independent experiment was performed three times and data are presented as mean $\pm \mathrm{SD}$. 
Table I. Primer sequences used for PCR.

\begin{tabular}{|c|c|c|}
\hline Gene & Primer sequences & Product size, bp \\
\hline \multirow[t]{2}{*}{ Pim-3 } & Forward: 5'-CACTGACTTTGATGGCACCC-3' & 770 \\
\hline & Reverse: 5'-ATGCCCAGACGAAGACCAG-3' & \\
\hline \multirow[t]{2}{*}{ IL-6 } & Forward: 5'-GTAGCCGCCCCACACAGACAGCC-3' & 174 \\
\hline & Reverse: 5'-GCCATCTTTGGAAGGTTCAGG-3' & \\
\hline \multirow[t]{2}{*}{ IL-1 $\beta$} & Forward: 5'-CCTTCTTTTCCTTCATCTTTG-3' & 372 \\
\hline & Reverse: 5'-ACCGCTTTTCCATCTTCTTCT-3' & \\
\hline \multirow[t]{2}{*}{ TNF- $\alpha$} & Forward: 5'-CTGGGCAGCGTTTATTCT-3' & 249 \\
\hline & Reverse: 5'-TTGCTTCTTCCCTGTTCC-3' & \\
\hline \multirow[t]{2}{*}{ ICAM-1 } & Forward: 5'-TCAAACGGGAGATGAATGG-3' & 230 \\
\hline & Reverse: 5'-CСТCСТCCTGAGCCTTCTG-3' & \\
\hline \multirow[t]{2}{*}{ Occludin } & Forward: 5'-CTGTCTATGCTCGTCATCG-3' & 294 \\
\hline & Reverse: 5'-CATTCCCGATCTAATGACG-3' & \\
\hline \multirow[t]{2}{*}{$\beta$-actin } & Forward: 5'-AGAGGGAAATCGTGCGTGAC-3' & 445 \\
\hline & Reverse: 5'-TGGAAGGTGGACAGTGAGGC-3' & \\
\hline
\end{tabular}

ICAM, intercellular adhesion molecule; IL, interleukin; Pim-3, Pim-3 proto-oncogene, serine/threonine kinase; TNF, tumor necrosis factor.

$R T-P C R$. After $48 \mathrm{~h}$ of LPS treatment, total RNA was extracted from AR42J cells in each group using TRIzol ${ }^{\circledR}$, according to the manufacturer's protocol. A total of $2 \mu \mathrm{g}$ RNA was used as the template to synthesize first-strand cDNA using a M-MLV RT kit. The reverse transcription temperature protocol used was $37^{\circ} \mathrm{C}$ for $15 \mathrm{~min}$ and $85^{\circ} \mathrm{C}$ for $30 \mathrm{sec}$. The PCR primer sequences were designed using Primer Premier 5.0 software (PREMIER Biosoft; Table I). PCR was performed with 500 ng cDNA, $1 \mu l$ sense primer, $1 \mu l$ antisense primer and $12.5 \mu 12 \mathrm{X}$ Taq PCR MasterMix; $\mathrm{ddH}_{2} \mathrm{O}$ was added to create a final volume of $25 \mu \mathrm{l}$. PCR was performed using the following thermal cycling conditions: Pre-denaturation at $94^{\circ} \mathrm{C}$ for $5 \mathrm{~min}$; 35 cycles of denaturation at $94^{\circ} \mathrm{C}$ for $45 \mathrm{sec}$, primer annealing at $55^{\circ} \mathrm{C}$ for $45 \mathrm{sec}$, primer extension at $72^{\circ} \mathrm{C}$ for $55 \mathrm{sec}$; and a final extension at $72^{\circ} \mathrm{C}$ for $7 \mathrm{~min}$. PCR products were electrophoresed on a $1.5 \%$ agarose gel and stained with ethidium bromide and subjected to densitometric scanning, and the bands were semi-quantified with NIH Image 1.62 (National Institutes of Health). The mRNA expression levels were normalized to $\beta$-actin.

Western blot analysis. After $48 \mathrm{~h}$ of LPS treatment, total protein was extracted using a total protein extraction kit and the protein concentration was measured using the BCA assay kit, according to the manufacturer's protocol. A total of $30 \mu \mathrm{g}$ protein was loaded on a $10 \%$ SDS-polyacrylamide gel, electrophoresed and transferred onto a nitrocellulose membrane. Membranes were blocked in 5\% non-fat milk for $1 \mathrm{~h}$ at room temperature. The membranes were probed with Pim-3, IL-6, IL-1 $\beta$, TNF- $\alpha$, ICAM-1, Occludin or $\beta$-actin antibodies overnight at $4^{\circ} \mathrm{C}$, followed by incubation with horseradish peroxidase-conjugated secondary antibodies at room temperature for $2 \mathrm{~h}$. Antibody probes on the membranes were detected using an ECL substrate kit (Shanghai Xuanling Biotechnology Co., Ltd.) and exposed to X-ray film. Semi-quantification of bands was carried out by scanning the films. The densities of the protein bands were quantified using Image J 1.8.0 software (National Institutes of Health). $\beta$-actin was used as a loading control.

Statistical analysis. All experiments in this study were repeated at least three times, and the final data are presented as mean \pm SD. Statistical significance was evaluated using one-way ANOVA among $\geq 3$ groups and LSD t-test post hoc test between 2 groups, using SPSS 19.0 (IBM Corp.). $\mathrm{P}<0.05$ was considered to indicate a statistically significant difference.

\section{Results}

pEGFP-N2 and pEGFP-N2/Pim-3 plasmids were successfully transfected into AR42J cells. In the presence of Lipofectamine ${ }^{\circledR} 2000$, pEGFP-N2 or pEGFP-N2/Pim-3 plasmids were transiently transfected into the AR42J cells. After $48 \mathrm{~h}$, these cells were observed using a fluorescence microscope. As shown in Fig. 1, the cells were successfully transfected with pEGFP-N2 and pEGFP-N2/Pim-3 as shown by $\mathrm{EGFP}^{+}$green fluorescence.

LPS-treated AR42J cells exhibit a dose-dependent reduction in cell proliferation. As shown in Fig. 2A, AR42J cell proliferation was measured following treatment with 1,2 and $4 \mu \mathrm{g} / \mathrm{ml}$ LPS using MTT assays. A concentration of $1 \mu \mathrm{g} / \mathrm{ml}$ LPS had little effect on the proliferation of AR42J cells, and there was no significantly difference compared to the control group. A concentration of $4 \mu \mathrm{g} / \mathrm{ml}$ LPS had a fatal effect on the AR42J cells and the cell viability was considered too poor to continue with this treatment. A concentration of $2 \mu \mathrm{g} / \mathrm{ml}$ LPS had a pronounced effect on the proliferation of AR42J cells and cell viability recovered significantly after $48 \mathrm{~h}$ of LPS treatment. Notably, $2 \mu \mathrm{g} / \mathrm{ml}$ LPS was the most suitable concentration and selected for subsequent experiments. 
Table II. Effects of Pim-3 on AR42J cell proliferation following LPS treatment.

\begin{tabular}{lccc}
\hline & \multicolumn{3}{c}{ Optical density } \\
\cline { 2 - 4 } Treatment group & $24 \mathrm{~h}$ & $36 \mathrm{~h}$ & $48 \mathrm{~h}$ \\
\hline Control & $0.7023 \pm 0.0114$ & $0.6924 \pm 0.0145$ & $0.7303 \pm 0.0308$ \\
pEGFP-N2 & $0.7158 \pm 0.0103$ & $0.7053 \pm 0.0115$ & $0.7765 \pm 0.0045$ \\
pEGFP-N2/Pim-3 & $0.7169 \pm 0.0204$ & $0.7391 \pm 0.0276$ & $0.7837 \pm 0.0105$ \\
LPS & $0.3983 \pm 0.0074^{\mathrm{a}}$ & $0.2642 \pm 0.0148^{\mathrm{a}}$ & $0.3654 \pm 0.0119^{\mathrm{a}}$ \\
pEGFP-N2 + LPS & $0.3841 \pm 0.0193^{\mathrm{a}}$ & $0.2554 \pm 0.0215^{\mathrm{a}}$ & $0.3565 \pm 0.0127^{\mathrm{a}}$ \\
pEGFP-N2/Pim-3 + LPS & $0.5284 \pm 0.0086^{\mathrm{a}, \mathrm{b}}$ & $0.3954 \pm 0.0115^{\mathrm{a}, \mathrm{b}}$ & $0.4417 \pm 0.0157^{\mathrm{a}, \mathrm{c}}$ \\
\hline
\end{tabular}

Data are expressed as the mean $\pm \mathrm{SD}, \mathrm{n}=12 .{ }^{\mathrm{a}} \mathrm{P}<0.01 \mathrm{vs}$. the control group, $\mathrm{pEGFP}-\mathrm{N} 2$ group and $\mathrm{pEGFP}-\mathrm{N} 2 / \mathrm{Pim}-3$ group. ${ }^{\mathrm{b}} \mathrm{P}<0.01 \mathrm{vs}$. the LPS group and pEGFP-N2 + LPS group. ${ }^{c} \mathrm{P}<0.05$ vs. the LPS group and pEGFP-N2 + LPS group. EGFP, enhanced green fluorescent protein; LPS, lipopolysaccharide; Pim-3, Pim-3 proto-oncogene, serine/threonine kinase.
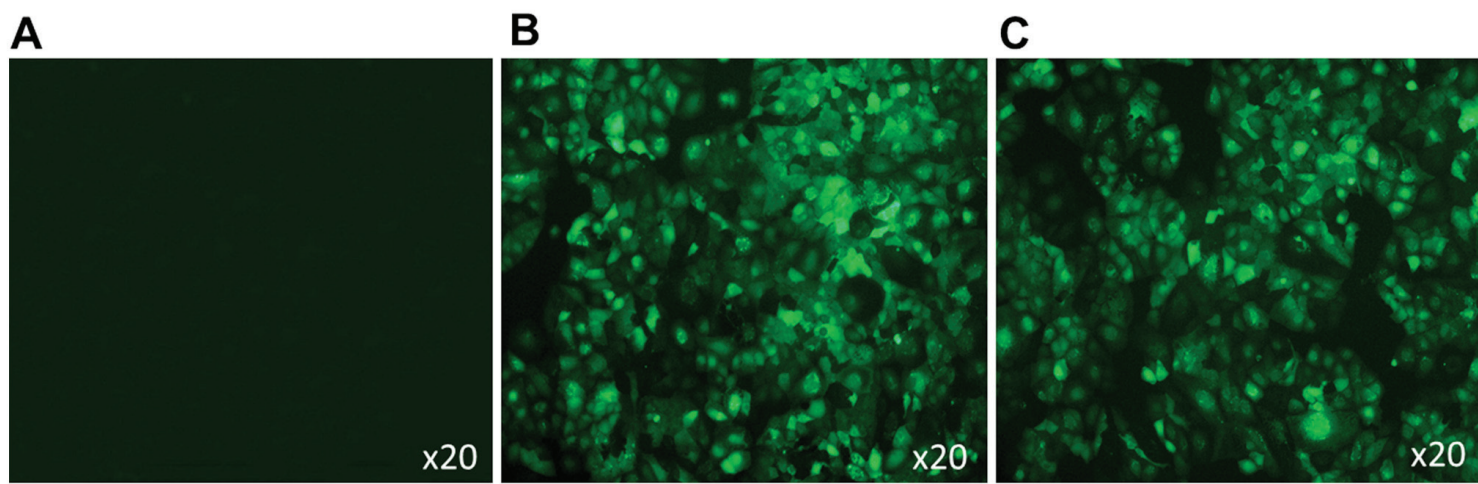

Figure 1. Successful transfection of the empty plasmid pEGFP-N2 and the recombinant plasmid pEGFP-N2/Pim-3. (A) Control, (B) pEGFP-N2 and (C) pEGFP-N2/Pim-3 groups. Cells were transfected using Lipofectamine ${ }^{\circledR} 2000$ for $48 \mathrm{~h}$. In the pEGFP-N2 and pEGFP-N2/Pim-3 groups, green fluorescence demonstrated successful incorporation of the vectors. EGFP, enhanced green fluorescent protein; Pim-3, Pim-3 proto-oncogene, serine/threonine kinase.

Pim-3 increases the proliferation of impaired AR42J cells. As shown in Table II and Fig. 2B, the optical density (OD) of the pEGFP-N2/Pim-3 + LPS group was higher than that in the LPS group and the pEGFP-N2 + LPS group (LPS for 24 and $36 \mathrm{~h}$, $\mathrm{P}<0.01$; LPS for $48 \mathrm{~h}, \mathrm{P}<0.05)$. The OD value in the LPS group was significantly lower than that in the control group $(\mathrm{P}<0.01)$. There was no significant difference in $\mathrm{OD}$ value between the control group, the pEGFP-N2 group and the pEGFP-N2/Pim-3 group $(\mathrm{P}>0.05)$. These results indicated that $\mathrm{Pim}-3$ increased the proliferation of injured pancreatic cells, but had no effect on normal pancreatic cells.

Pim-3 inhibits the apoptosis of AR42J cells following LPS treatment. The total apoptosis rate of AR42J cells in the pEGFP-N2/Pim-3 + LPS group was significantly lower than that in the LPS group and the pEGFP-N2 + LPS group $(\mathrm{P}<0.01)$. The total apoptosis rate in the LPS group was higher than that in the control group $(\mathrm{P}<0.01)$. There was no significant difference in the total apoptosis rate between the control group, the pEGFP-N2 group and the pEGFP-N2/Pim-3 group ( $\mathrm{P}>0.05$; Fig. 2C and D).

Pim-3 can regulate cell cycle progression of AR42J cells after LPS treatment. The percentage of AR42J cells in G1 phase in the pEGFP-N2/Pim-3 + LPS group decreased significantly, whereas the proportion of cells in the S and G2 phases increased compared with in the LPS group and the pEGFP-N2 + LPS group $(\mathrm{P}<0.05, \mathrm{P}<0.05$ and $\mathrm{P}<0.01$, respectively). The proportion of cells in the G1 phase in the LPS group was significantly increased, whereas the proportion of cells in the $\mathrm{S}$ and $\mathrm{G} 2$ phases was decreased compared with in the control group $(\mathrm{P}<0.01)$. There was no significant difference in the proportions of cells in the various cell cycle phases between the control group, the pEGFP-N2 group and the pEGFP-N2/Pim-3 group $(\mathrm{P}>0.05)$ (Fig. 2E and $\mathrm{F})$.

Pim-3 promotes impaired AR42J cell migration. As shown in Fig. 3A and B, LPS significantly inhibited the migration of AR42J cells (LPS group vs. control group, 51.53 $\pm 0.49 \%$ vs. $77.52 \pm 0.97 \%, \mathrm{P}<0.01)$. Whereas, the migration of AR42J cells in the pEGFP-N2/Pim-3 + LPS group was markedly increased compared with in the LPS group and the pEGFP-N2 + LPS group (pEGFP-N2/Pim-3 + LPS group vs. LPS group or pEGFP-N2 + LPS group, $68.68 \pm 1.11 \%$ vs. $51.53 \pm 0.49 \%$ or $55.12 \pm 1.87 \%$, respectively, $\mathrm{P}<0.01$ ). There was no significant difference in cell migration between the control group, the pEGFP-N2 group and the pEGFP-N2/Pim-3 group ( $\mathrm{P}>0.05)$. 
A

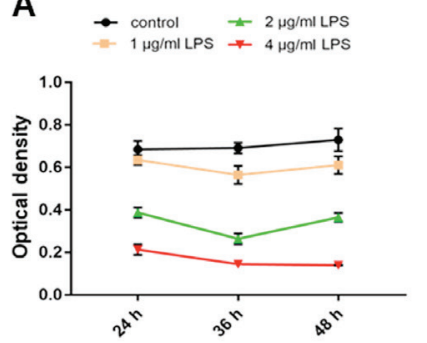

C

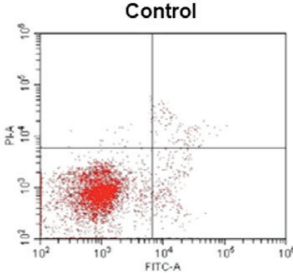

pEGFP-N2

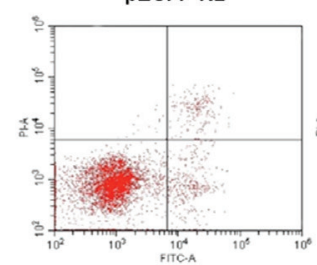

PEGFP-N2/Pim-3

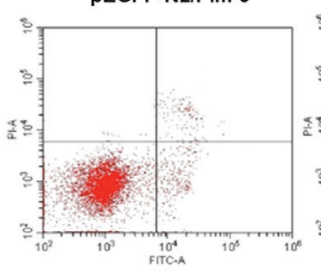

E

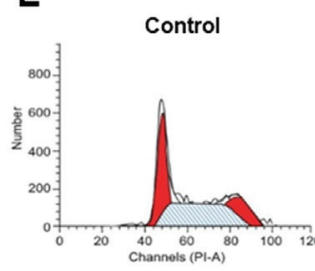

pEGFP-N2

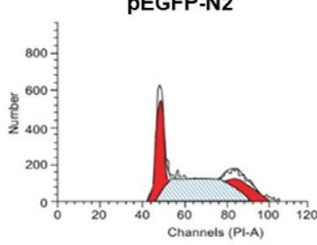

pEGFP-N2/Pim-3

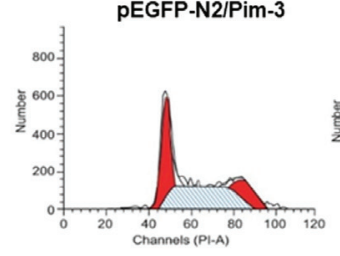

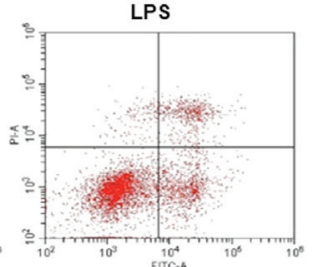

PEGFP-N2+LPS

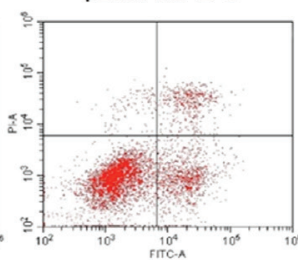

pEGFP-N2/Pim-3+LPS

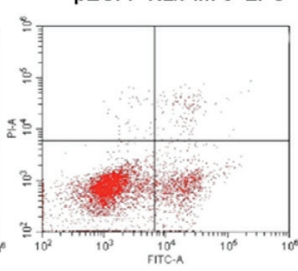

B $\rightarrow$ conted $\rightarrow$ LPS

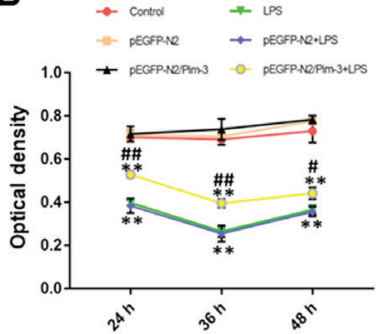

D

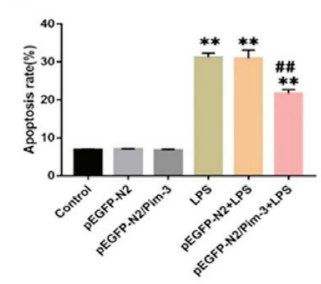

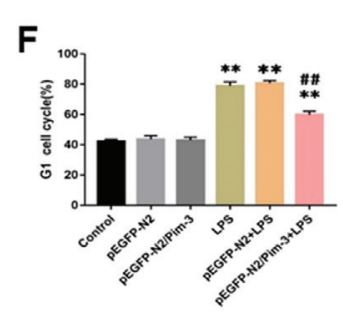

pEGFP-N2+LPS
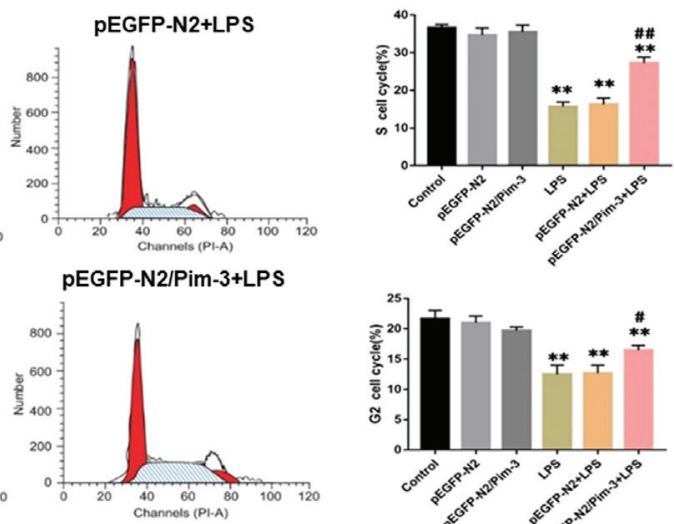

Figure 2. Effect of Pim-3 on AR42J cell growth following LPS treatment. (A) AR42J cells were treated with various concentrations of LPS and proliferation was measured using an MTT assay (optical density increases with cell proliferation). (B) After transfection for $48 \mathrm{~h}$, AR42J cells were treated with LPS for 24, 36 and $48 \mathrm{~h}$. Proliferation was then measured using an MTT assay. (C) After transfection for $48 \mathrm{~h}$, AR42J cells were treated with LPS for $48 \mathrm{~h}$ and the cells were subjected to combined staining with FITC-Annexin V and PI. Cell apoptosis was determined by flow cytometry and (D) apoptosis rates were compared. (E) After transfection for $48 \mathrm{~h}$, AR42J cells were treated with LPS for $48 \mathrm{~h}$. The cells were then treated with $40 \mu \mathrm{g} / \mathrm{ml}$ PI. The distribution of the cell cycle phases was determined using a flow cytometer and (F) the percentage of cells in G1, S and G2 are displayed. Data are expressed as the mean \pm SD, $\mathrm{n}=12$ for all groups in (A) and (B) or $\mathrm{n}=6$ for all groups in $(\mathrm{C}, \mathrm{D}$, and $\mathrm{E}) .{ }^{* *} \mathrm{P}<0.01$ vs. the control group, pEGFP-N2 group and pEGFP-N2/Pim-3 group. ${ }^{*} \mathrm{P}<0.05$ vs. the LPS group and pEGFP-N2 + LPS group. ${ }^{\#} \mathrm{P}<0.01$ vs. the LPS group and pEGFP-N2 + LPS group. EGFP, enhanced green fluorescent protein; LPS, lipopolysaccharide; PI, propidium iodide; Pim-3, Pim-3 proto-oncogene, serine/threonine kinase. 
A

$0 \mathrm{~h}$

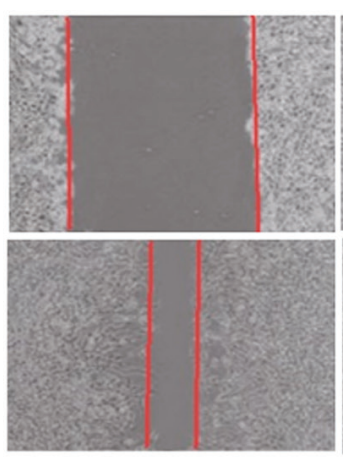

LPS

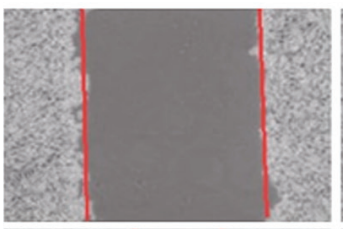

$48 \mathrm{~h}$

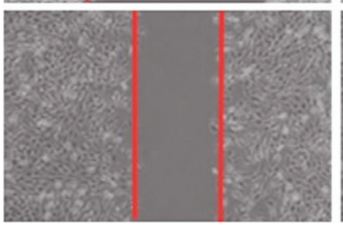

pEGFP-N2

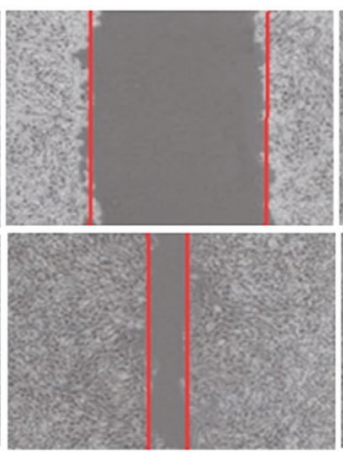

pEGFP-N2+LPS

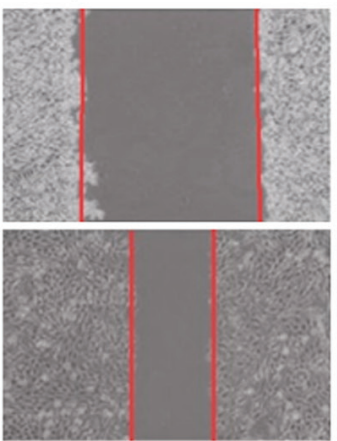

pEGFP-N2/Pim-3

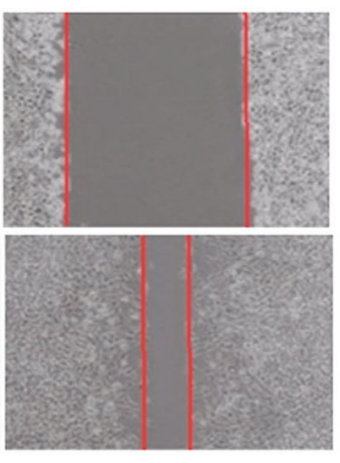

PEGFP-N2/Pim-3+LPS

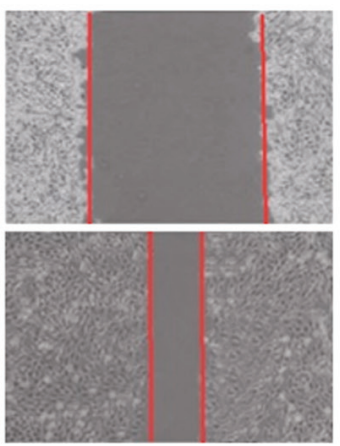

B

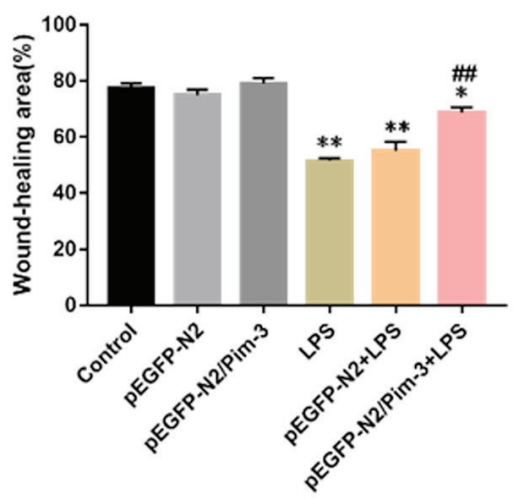

Figure 3. Effect of Pim-3 on AR42J cell migration following LPS treatment. (A) After transfection for $48 \mathrm{~h}$, the AR42J cell monolayers were scraped with a sterile $10-\mu 1$ micropipette tip to create a longitudinal scratch of constant width. The cells were then incubated with $2 \mu \mathrm{g} / \mathrm{ml} \mathrm{LPS}$ for $48 \mathrm{~h}$. The wound healing of different groups was observed using microscopy (magnification, x100). (B) The ability of the cells to close the wound was calculated by measuring the average distance of the wound edge of the scratched space and calculating the percentage of the wound that had been closed. Data are expressed as the mean $\pm \mathrm{SD}, \mathrm{n}=6$. ${ }^{* *} \mathrm{P}<0.01$ vs. the control group, pEGFP-N2 group and $\mathrm{pEGFP}-\mathrm{N} 2 / \mathrm{Pim}-3$ group. ${ }^{*} \mathrm{P}<0.05$ vs. the control group, $\mathrm{pEGFP-N2}$ group and $\mathrm{pEGFP-N2/Pim-3}$ group. ${ }^{\#} \mathrm{P}<0.01$ vs. the LPS group and pEGFP-N2 + LPS group. EGFP, enhanced green fluorescent protein; LPS, lipopolysaccharide; Pim-3, Pim-3 proto-oncogene, serine/threonine kinase.

Pim-3 regulates $I L-6, I L-1 \beta, T N F-\alpha, I C A M-1$ and Occludin mRNA expression in the impaired AR42J cells. The relative mRNA expression levels of Pim-3 in the pEGFP-N2/Pim-3 group and the pEGFP-N2/Pim-3 + LPS group were markedly elevated compared with in the control group, the pEGFP-N2 group, the LPS group and the pEGFP-N2 + LPS group $(\mathrm{P}<0.01)$. The mRNA expression levels of IL-6, IL-1 $\beta$, TNF- $\alpha$ and ICAM-1 in the LPS group were significantly increased compared with in the control group, whereas Occludin mRNA expression was significantly decreased $(\mathrm{P}<0.01)$. However, the mRNA expression levels of IL-6, IL-1 $\beta$, TNF- $\alpha$, and ICAM-1 in the pEGFP-N2/Pim-3 + LPS group were significantly decreased compared with in the LPS group and the pEGFP-N2 + LPS group $(\mathrm{P}<0.01, \mathrm{P}<0.01, \mathrm{P}<0.05$ and $\mathrm{P}<0.01$, respectively), whereas the expression levels of Occludin mRNA were increased $(\mathrm{P}<0.05)$. There was no significant difference between the mRNA expression levels of all of the measured transcripts between the control group, the pEGFP-N2 group and the pEGFP-N2/Pim-3 group ( $\mathrm{P}>0.05)$ (Fig. 4A and B).

Pim-3 regulates $I L-6, I L-1 \beta, T N F-\alpha, I C A M-1$ and Occludin protein expression in the impaired AR42J cells. As shown in Fig. $4 \mathrm{C}$ and D, the relative protein expression levels of Pim-3 in the pEGFP-N2/Pim-3 group and pEGFP-N2/Pim-3 + LPS group were significantly increased compared with in the control group, the pEGFP-N2 group, the LPS group and the
pEGFP-N2 + LPS group $(\mathrm{P}<0.01)$. The protein expression levels of IL-6, IL-1 $\beta$, TNF- $\alpha$, and ICAM-1 were markedly elevated in the LPS group compared with in the control group, whereas Occludin protein expression was reduced after LPS treatment $(\mathrm{P}<0.01)$. Conversely, the relative protein expression levels of IL-6, IL-1 $\beta$, TNF- $\alpha$ and ICAM-1 in the pEGFP-N2/Pim-3 + LPS group were markedly reduced compared with the LPS group and the pEGFP-N2 + LPS group $(\mathrm{P}<0.01, \mathrm{P}<0.05, \mathrm{P}<0.01$ and $\mathrm{P}<0.01$, respectively), whereas Occludin protein expression was increased $(\mathrm{P}<0.05)$. There was no significant difference in protein expression levels of IL-6, IL-1 $\beta$, TNF- $\alpha$, ICAM-1 and Occludin between the control group, the pEGFP-N2 group and the pEGFP-N2/Pim-3 group ( $\mathrm{P}>0.05)$.

\section{Discussion}

AP is a common acute abdominal malignancy. A previous study found that $\sim 30 \%$ of patients with AP will experience severe attacks, which are associated with a high mortality rate (19). AP manifests as localized inflammation, which is amplified by the action of various inflammatory mediators, such as cytokines, reactive oxygen species, chemokines, leukocyte adhesion molecules and lipids, resulting in pancreatic inflammation (20-22). The present study also showed that the expression levels of IL-6, IL-1 $\beta$, TNF- $\alpha$, and ICAM-1 in AR42J cells stimulated by LPS were markedly higher than in the control group. Although the pathogenesis behind AP or 
A
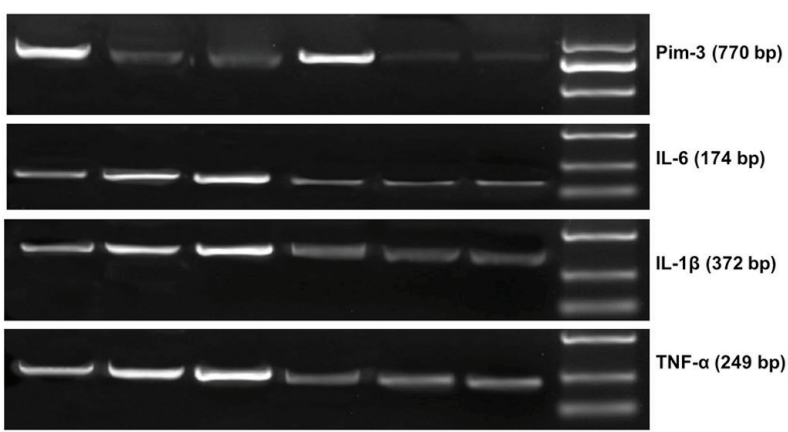

IL-1 $\beta$ (372 bp)

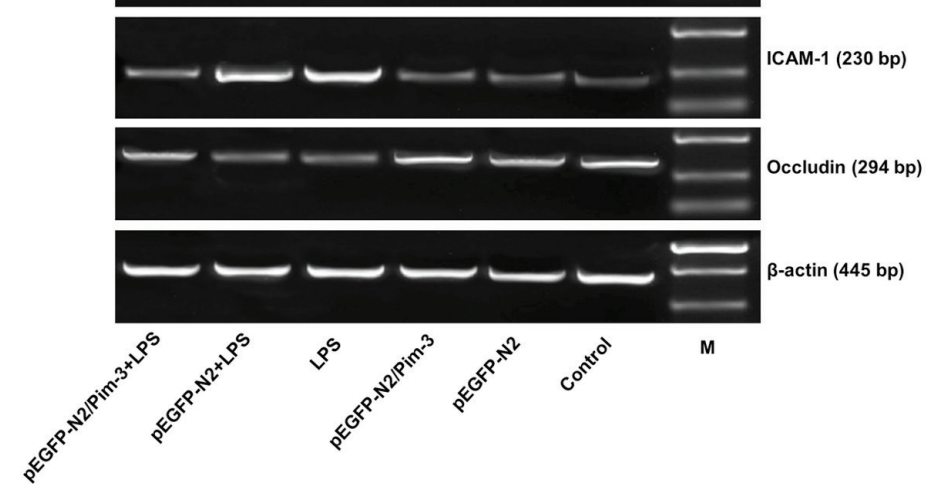

TNF- $\alpha(249 \mathrm{bp})$

C

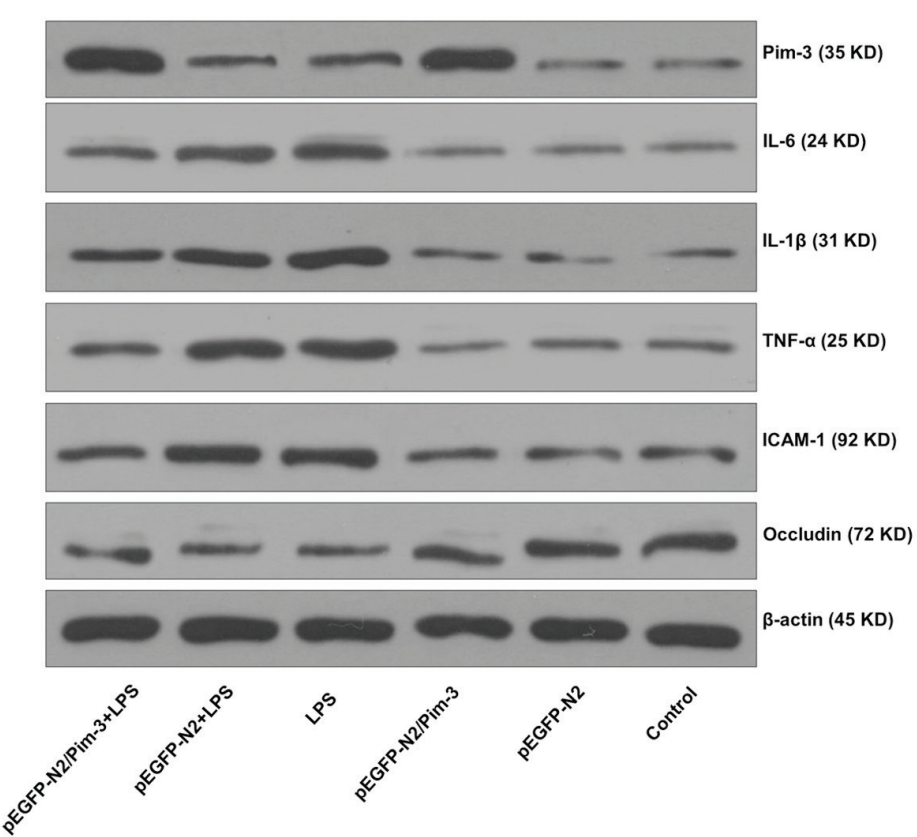

B
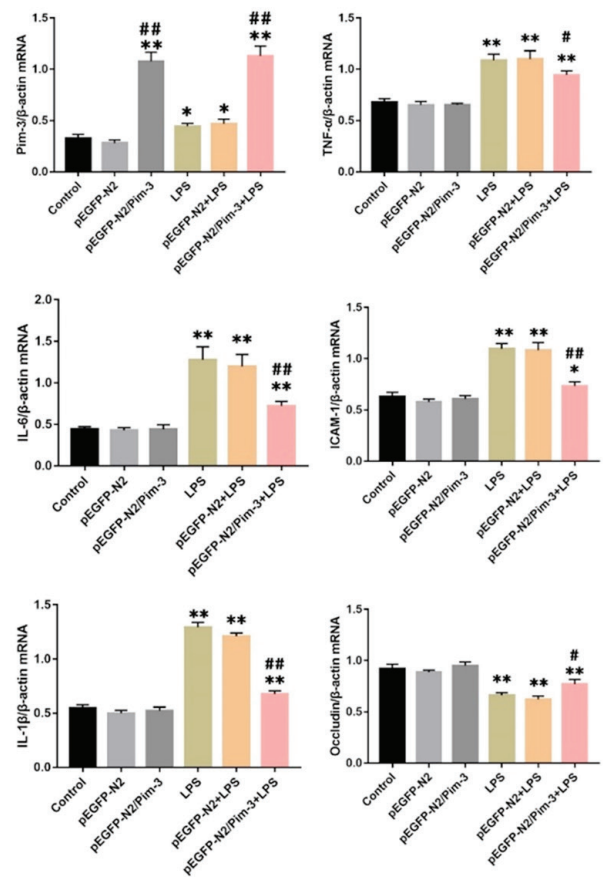

D
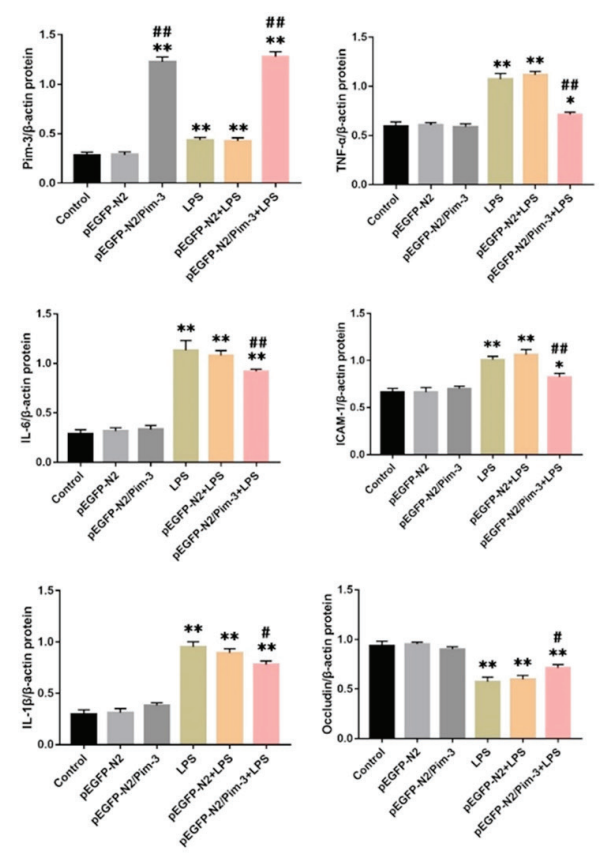

Figure 4. Changes in mRNA and protein expression levels of Pim-3, IL-6, IL-1 $\beta$, TNF- $\alpha$, ICAM-1 and Occludin in AR42J cells following LPS treatment. After transfection for $48 \mathrm{~h}$, AR42J cells were treated with LPS for $48 \mathrm{~h}$. (A) PCR bands demonstrating the relative mRNA expression levels of Pim-3, IL-6, IL-1 $\beta$, TNF- $\alpha$, ICAM-1 and Occludin. (B) Bands were semi-quantified to compare changes in expression levels. (C) Relative protein expression levels of Pim-3, IL-6, IL-1 $\beta$, TNF- $\alpha$, ICAM-1 and Occludin. (D) Bands were semi-quantified to compare changes in expression levels. Control group (no treatment); pEGFP-N2 group (48 h after pEGFP-N2 transfection); pEGFP-N2/Pim-3 group (48 h after pEGFP-N2/Pim-3 transfection); LPS group (48 h of LPS treatment); pEGFP-N2 + LPS group (48 h after pEGFP-N2 transfection and LPS treatment for $48 \mathrm{~h}$ ); pEGFP-N2/Pim-3 + LPS group (48 h after pEGFP-N2/Pim-3 transfection and LPS treatment for 48 h); M, DL2000 DNA marker. Data are expressed as the mean $\pm \mathrm{SD}, \mathrm{n}=6$. ${ }^{*} \mathrm{P}<0.05$ vs. the control group, pEGFP-N2 group and pEGFP-N2/Pim-3 group. ${ }^{* *} \mathrm{P}<0.01$ vs. the control group, pEGFP-N2 group and pEGFP-N2/Pim-3 group. ${ }^{*} \mathrm{P}<0.05$ vs. the LPS group and pEGFP-N2 + LPS group. ${ }^{\#} \mathrm{P}<0.01$ vs. the LPS group and pEGFP-N2 + LPS group. EGFP, enhanced green fluorescent protein; LPS, lipopolysaccharide; ICAM, intercellular adhesion molecule; IL, interleukin; Pim-3, Pim-3 proto-oncogene, serine/threonine kinase; TNF, tumor necrosis factor.

SAP has been extensively studied, the exact mechanism of action has not been fully elucidated. Because the pathogenesis is still unclear, AP presents a common clinical challenge (23).
Pim-3 is a serine/threonine kinase, which is involved in numerous cellular processes, including cell proliferation, survival and apoptosis (24). Pim-3 is overexpressed in cancerous tissue of 
endoderm-derived organs, such as the liver, pancreas, stomach and colon (12-14,25). Pim-3 can regulate the proliferation, survival, angiogenesis and apoptosis of pancreatic cancer cells (26). Furthermore, downregulating Pim-3 expression causes pancreatic cancer cells to become more sensitive to chemotherapy and radiotherapy $(27,28)$. Recent studies have demonstrated that Pim-3 has protective effects on fulminant hepatic failure, damaged intestinal mucosa and LPS-stimulated hepatic stellate cells (16-18). In this present study, it was found that Pim-3 could prevent the apoptosis of pancreatic acinar cells injured by LPS and promote the survival of pancreatic acinar cells. In addition, Pim-3 regulated the cell cycle of pancreatic acinar cells and enhanced their motor ability, appearing to protect the damaged AR42J cells.

Proinflammatory cytokines, including IL-6, IL-1 $\beta$ and TNF- $\alpha$, are considered to serve a prominent role in the occurrence and progression of AP or SAP. Previous studies have reported that IL- 6 has a crucial role in the early stages of inflammation, and TNF- $\alpha$, another important inflammatory factor, can mediate the initiation and progression of AP (29-31). IL-1 $\beta$ and TNF- $\alpha$ serve an important role in the pathogenesis of AP or SAP, leading to inflammation, edema and necrosis (32). Adhesion molecules are thought to be involved in activating leukocyte rolling, binding to vascular tissue and initiating inflammatory cascade (33). ICAM-1 is an important adhesion molecule in regulating leukocyte adhesion (34). During inflammation, ICAM-1 binds to integrin subunit $\alpha \mathrm{L}$ and integrin subunit $\beta 2$, two integrins expressed by leukocytes, promoting cell adhesion and transepithelial migration (35). It has been reported that ICAM-1 expression is elevated during AP and its expression levels are closely related to the severity of the disease $(36,37)$. Tight junctions are the major apical structures of epithelial and endothelial cells, playing an important role in the cell barrier by forming intercellular contacts and physically blocking paracellular pathways $(38,39)$. Occludin is an important structural protein in the tight junctions of endothelial cells. Occludin forms a tight extracellular zipper by bringing opposing outer membrane surfaces of cells in contact to regulate barrier function. It can also bind to various molecules and induce signaling pathways, allowing Occludin to participate in the regulation of tight junction formation (40). In caerulein-induced AP rats, the loss of Occludin precedes the elevation of serum lipase and amylase, and is linked with an increase in extracellular permeability, suggesting that Occludin may serve an important role in pancreatic barrier function $(41,42)$. The present study also revealed that the expression levels of IL-6, IL-1 $\beta$, TNF- $\alpha$ and ICAM-1 were markedly increased in pancreatic acinar cells after LPS stimulation, whereas the expression of Occludin was significantly reduced after LPS intervention. These results also showed that the transfection of exogenous Pim-3 into the AR42J cells prior to LPS treatment, not only significantly reduced the expression of pro-inflammatory cytokines, such as IL-6, IL-1 $\beta$, TNF- $\alpha$, and ICAM-1, but also promoted the expression of Occludin, thus abating the pancreatic injury mediated by LPS.

In summary, the present study revealed that exogenous Pim-3 could alleviate pancreatic acinar cell injury induced by LPS by reducing the expression of IL-6, IL-1 $\beta$, TNF- $\alpha$ and ICAM-1, and promoting Occludin expression. Pim-3 may function to protect damaged pancreatic acinar cells through regulating the inflammatory responses in the microenvironment. As such, Pim-3 has a great potential for use as a therapeutic gene for treating AP or SAP.

\section{Acknowledgements}

The authors would like to thank Dr Xia Gan, Dr Li-Hong Gan, Dr Ya-Qing Huang and Dr Ling Yao (Department of Gastroenterology, Third Affiliated Hospital of Nanchang University) for their helpful suggestions regarding the writing of this manuscript.

\section{Funding}

This study was supported by the Health and Family Planning Commission Science and Technology Plan of Jiangxi Province (grant no. 20184002).

\section{Availability of data and materials}

The datasets used and/or analyzed during the present study are available from the corresponding author on reasonable request.

\section{Authors' contributions}

$\mathrm{JJ}$ and NF designed the experiments. JJ, SL, YZC, JBQ, BL and $\mathrm{LZ}$ performed the experiments. JJ contributed to the analysis of the data and wrote the manuscript. NF corrected the manuscript. All authors read and approved the final manuscript.

\section{Ethics approval and consent to participate}

Not applicable.

\section{Patient consent for publication}

Not applicable.

\section{Competing interests}

The authors declare that they have no competing interests.

\section{References}

1. Lankisch PG, Apte M and Banks PA: Acute pancreatitis. Lancet 386: 85-96, 2015.

2. Zerem E: Treatment of severe acute pancreatitis and its complications. World J Gastroenterol 20: 13879-13892, 2014.

3. Jeong YK, Lee S, Lim JW and Kim H: Docosahexaenoic acid inhibits cerulein-induced acute pancreatitis in rats. Nutrients 9: E744, 2017.

4. Wang G, Liu Y, Zhou SF, Qiu P, Xu L, Wen P, Wen J and Xiao X: Effect of somatostatin, ulinastatin and gabexate on the treatment of severe acute pancreatitis. Am J Med Sci 351: 506-512, 2016.

5. Murata A, Ohtani M, Muramatsu K and Matsuda S: Effects of proton pump inhibitor on outcomes of patients with severe acutepancreatitis based on a national administrative database. Pancreatology 15: 491-496, 2015.

6. Nesseler N, Ross JT and Mallédant Y: Infected necrotizing pancreatitis: Antibiotic administration remains the first step. Lancet 391: 2501-2502, 2018.

7. Gorskii VA, Agapov MA, Khoreva MV, Petrov VA, Kravchenko AY and Battaev AI: Effect of lornoxicam therapy on expression of TLR2 and TLR4 mRNA during systemic complications of acute pancreatitis. Bull Exp Bio Med 158: 13-15, 2014. 
8. Sherman MH, Yu RT, Engle DD, Ding N, Atkins AR, Tiriac $H$, Collisson EA, Connor F, Van Dyke T, Kozlov S, et al: Vitamin D receptor-mediated stromal reprogramming suppresses pancreatitis and enhances pancreatic cancer therapy. Cell 159: 80-93, 2014.

9. Hua J, He ZG, Qian DH, Lin SP, Gong J, Meng HB, Yang TS, Sun W, Xu B, Zhou B and Song ZS: Angiopoietin-1 genemodified human mesenchymal stem cells promote angiogenesis and reduce acute pancreatitis in rats. Int J Clin Exp Pathol 7: 3580-3595, 2014.

10. Liu J, Qu X, Shao L, Hu Y, Yu X, Lan P, Guo Q, Han Q, Zhang J and Zhang C: Pim-3 enhances melanoma cell migration and invasion by promoting STAT3 phosphorylation. Cancer Biol Ther 19: 160-168, 2018.

11. Narlik-Grassow M, Blanco-Aparicio C and Carnero A: The PIM family of Serine/Threonine kinases in cancer. Med Res Rev 34 136-159, 2014

12. Fujii C, Nakamoto Y, Lu P, Tsuneyama K, Popivanova BK, Kaneko S and Mukaida N: Aberrant expression of serine/threonine kinase Pim-3 in hepatocellular carcinoma development and its role in the proliferation of human hepatoma cell lines. Int J Cancer 114: 209-218, 2005

13. Li YY, Popivanova BK, Nagai Y, Ishikura H, Fujii $\mathrm{C}$ and Mukaida N: Pim-3, a proto-oncogene with serine/threonine kinase activity, is aberrantly expressed in human pancreatic cancer and phosphorylates bad to block bad-mediated apoptosis in human pancreatic cancer cell lines. Cancer Res 66: 6741-6747, 2006.

14. Popivanova BK, Li YY,Zheng H, Omura K, Fujii C, Tsuneyama K and Mukaida N: Proto-oncogene, Pim-3 with serine/threonine kinase activity, is aberrantly expressed in human colon cancer cells and can prevent Bad-mediated apoptosis. Cancer Sci 98: 321-328, 2007.

15. Mukaida N, Wang YY and Li YY: Roles of Pim-3, a novel survival kinase, in tumorigenesis. Cancer Sci 102: 1437-1442, 2011.

16. Liu LM, Zhang JX, Wang XP, Guo HX, Deng H and Luo J: Pim-3 protects against hepatic failure in D-galactosamine (D-GalN)-sensitized rats. Eur J Clin Invest 40: 127-138, 2010.

17. Chen JY, Shen XW and Zhang JX: Protective role of Pim-3 gene in intestinal mucosa damaged by burn or lipopolysaccharide. Zhonghua Yi Xue Za Zhi 87: 2960-2964, 2007 (In Chinese).

18. Liu LH, Lai QN, Chen JY, Zhang JX and Cheng B: Overexpression of pim-3 and protective role in lipopolysaccharide-stimulated hepatic stellate cells. World J Gastroenterol 21: 8858-8867, 2015

19. Cai F, Cui N, Ma H, Wang X, Qiao G and Liu D Interleukin-10-1082A/G polymorphism is associated with the development of acute pancreatitis in a Chinese population. Int J Clin Exp Pathol 8: 15170-15176, 2015.

20. Simsek O, Kocael A, Kocael P, Orhan A, Cengiz M, Balci H, Ulualp $\mathrm{K}$ and Uzun $\mathrm{H}$ : Inflammatory mediators in the diagnosis and treatment of acute pancreatitis: Pentraxin3, procalcitonin and myeloperoxidase. Arch Med Sci 14: 288-296, 2018.

21. Ge N, Xia Q, Yang ZH, Ding QF and Zeng Z: Vascular endothelial injury and apoptosis in rats with severe acute pancreatitis. Gastroenterol Res Pract 2015: 235017, 2015.

22. Pan YL: The effects of glycyrrhizin on acute pancreatitis in mice. Eur Rev Med Pharmacol Sci 18: 3943-3947, 2014.

23. Banks PA: Acute pancreatitis: Landmark studies, management decisions, and the future. Pancreas 45: 633-640, 2016

24. Li YY and Mukaida N: Pathophysiological roles of Pim-3 kinase in pancreatic cancer development and progression. World $\mathrm{J}$ Gastroenterol 20: 9392-9404, 2014.

25. Zheng HC, Tsuneyama K, Takahashi H, Miwa S, Sugiyama T, Popivanova BK, Fujii C, Nomoto K, Mukaida $\mathrm{N}$ and Takano Y: Aberrant Pim-3 expression is involved in gastric adenoma-adenocarcinoma sequence and cancer progression. J Cancer Res Clin Oncol 134: 481-488, 2008.
26. Wang C, Li HY, Liu B, Huang S, Wu L and Li YY: Pim-3 promotes the growth of human pancreatic cancer in the orthotopic nude mouse model through vascular endothelium growth factor. J Surg Res 185: 595-604, 2013.

27. Liang C, Yu XJ, Guo XZ, Sun MH, Wang Z, Song Y, Ni QX, Li HY, Mukaida N and Li YY: MicroRNA-33a-mediated downregulation of Pim-3 kinase expression renders human pancreatic cancer cells sensitivity to gemcitabine. Oncotarget 6 : 14440-14455, 2015.

28. Chen XY, Wang Z, Li B, Zhang YJ and Li YY: Pim-3 contributes to radioresistance through regulation of the cell cycle and DNA damage repair in pancreatic cancer cells. Biochem Biophys Res Commun 473: 296-302, 2016.

29. Gregoric P, Sijacki A, Stankovic S, Radenkovic D, Ivancevic N, Karamarkovic A, Popovic N, Karadzic B, Stijak L, Stefanovic B, et al: SIRS score on admission and initial concentration of IL-6 as severe acute pancreatitis outcome predictors. Hepatogastroenterology 57: 349-353, 2010.

30. De Waele JJ and Blot S: The value of IL-6 in predicting the severity of acute pancreatitis. J Clin Gastroenterol 41: 534, 2007

31. Sternby H, Hartman H, Johansen D, Thorlacius H and Regnér S: IL-6 and CRP are superior in early differentiation between mild and non-mild acute pancreatitis. Pancreatology 17: 550-554, 2017.

32. Vonlaufen A, Apte MV, Imhof BA and Frossard JL: The role of inflammatory and parenchymal cells in acute pancreatitis. J Pathol 213: 239-248, 2007.

33. Rubant SA, Ludwig RJ, Diehl S, Hardt K, Kaufmann R, Pfeilschifter JM and Boehncke WH: Dimethylfumarate reduces leukocyte rolling in vivo through modulation of adhesion molecule expression. J Invest Dermatol 128: 326-331, 2008.

34. Dabrowski A, Osada J, Dabrowska MI, WereszczynskaSiemiatkowska U and Siemiatkowski A: Increased expression of the intercellular adhesion molecule-1 (ICAM-1) on peripheral blood neutrophils in acute pancreatitis. Adv Med Sci 59: 102-107, 2014.

35. Sun W, Watanabe $Y$ and Wang ZQ: Expression and significance of ICAM-1 and its counter receptors LFA-1 and Mac-1 in experimental acute pancreatitis of rats. World J Gastroenterol 12: 5005-5009, 2006.

36. Zhu HH and Jiang LL: Serum inter-cellular adhesion molecule 1 is an early marker of diagnosis and prediction of severe acute pancreatitis. World J Gastroenterol 18: 2554-2560, 2012.

37. Staubli SM, Oertli D and Nebiker CA: Laboratory markers predicting severity of acute pancreatitis. Crit Rev Clin Lab Sci 52: 273-283, 2015.

38. Shin K, Fogg VC and Margolis B: Tight junctions and cell polarity. Annu Rev Cell Dev Biol 22: 207-235, 2006.

39. Oliveira SS and Morgado-Díaz JA: Claudins: Multifunctional players in epithelial tight junctions and their role in cancer. Cell Mol Life Sci 64: 17-28, 2007.

40. Kojima T and Sawada N: Regulation of tight junctions in human normal pancreatic duct epithelial cells and cancer cells. Ann NY Acad Sci 1257: 85-92, 2012.

41. Xia XM, Li BK, Xing SM and Ruan HL: Emodin promoted pancreatic claudin-5 and occludin expression in experimental acute pancreatitis rats. World J Gastroenterol 18: 2132-2139, 2012.

42. Chen D, Li L, Yan J, Yang X, You Y, Zhou Y and Ling X: The loss of $\alpha$ SNAP downregulates the expression of occludin in the intestinal epithelial cell of acute pancreatitis model. Pancreatology 14: 347-355, 2014.

This work is licensed under a Creative Commons Attribution-NonCommercial-NoDerivatives 4.0 International (CC BY-NC-ND 4.0) License. 